\title{
Risk factors for BiPAP failure as an initial management approach in moderate to late preterm infants with respiratory distress
}

\begin{abstract}
Key message
Question: Which factors can predict BiPAP failure as the initial management approach for moderate to late preterm infants with respiratory distress?

Finding: RDS aggravation and increased oxygen and frequency requirements during BiPAP support were associated with BiPAP failure.

Meaning: Early changes to invasive ventilator care should be considered for moderate to late preterm infants showing RDS aggravation and increased oxygen and frequency requirements during BiPAP support.
\end{abstract}

\section{To the editor,}

Noninvasive ventilation (NIV) has been increasingly used instead of intermittent mandatory ventilation (IMV) as the initial respiratory management approach in preterm infants. Among various NIV strategies, bilevel positive airway pressure (BiPAP) was introduced in recent years as an alternative to conventional nasal continuous positive airway pressure (nCPAP). Theoretically, BiPAP should enable greater alveolar recruitment, a higher residual functional capacity, and reduced breath work compared to nCPAP. ${ }^{1,2)}$ Three retrospective observational studies and 2 randomized controlled trials reported the superiority of BiPAP over nCPAP for oxygenation and ventilation in preterm infants, although there are discrepancies among the reported results. 3-7) To the best of our knowledge, no study has reported the predictive risk factors for BiPAP failure. This study aimed to investigate risk factors for BiPAP failure as the initial respiratory management strategy in moderate to late preterm infants with respiratory distress.

This retrospective observational study included patients in the neonatal intensive care unit of Korea University Ansan Hospital from January 2014 to September 2018 who required BiPAP as the initial respiratory support within 24 hours after birth. Infants who required resuscitation with intubation in the delivery room and those who were diagnosed with chromosomal abnormalities or an air leak, cardiovascular instability, or multiple congenital anomalies were excluded. Since prophylactic surfactant administration is recommended for preterm infants who are born at a gestational age (GA) of less than $30^{+0}$ weeks or with a body weight (BW) less than or equal to 1,250 g in South Korea, they were excluded from the study.
One hundred twenty-two preterm infants were categorized into the success and failure groups. The success group included preterm infants successfully weaned from BiPAP within 7 days, while those in the failure group failed weaning and required intubation under any of the following circumstances: (1) aggravation of respiratory acidosis on a blood gas analysis after BiPAP application; (2) a fraction of inspired oxygen in the air greater than 0.4 to maintain a peripheral capillary oxygen saturation of $88 \%-94 \%$; and (3) more than 2-3 apnea episodes per hour requiring repeated stimulation or bag-and-mask ventilation.

Detailed data were collected, including information about pregnancy, labor, BiPAP settings, serial lab results during BiPAP, and causes of respiratory distress. Outcomes include rate of BiPAP failure; length of hospital stay; and the incidence of pneumothorax, bronchopulmonary dysplasia, symptomatic patent ductus arteriosus, periventricular leukomalacia, intraventricular hemorrhage (grade $\geq \mathrm{II}$ ), and necrotizing enterocolitis (stage $\geq 2$ ).

A significant intergroup difference was defined as a $P$ value less than 0.05 using an appropriate statistical test for categorical data $\left(\chi^{2}\right)$, continuous parametric data (Student $t$ test), and nonparametric (Wilcoxon Mann-Whitney) data. Variables statistically different between the success and failure groups were included in a multivariable logistic regression model in which BiPAP failure was the dependent variable.

Of 122 preterm infants in this study, the rate of BiPAP failure was $10.7 \%$ (13 of 122). Most of the patients' perinatal charac. teristics and maternal medical histories were similar between groups (Table 1). Nevertheless, BiPAP failure rates tended to increase as GA or BW decreased (data not shown). The incidence of respiratory distress syndrome (RDS) was significantly higher in the failure group. The need for surfactant administration was also higher in the failure group. The failure group also had a significantly higher oxygen frequency requirement during BiPAP support (Table 2). After adjustment for GA, multivariate analysis revealed that $\mathrm{RDS}$, oxygen requirement, and increased frequency during BiPAP support remained significant.

Regarding hospital outcomes, superiority over primarily practiced IMV was not noted in cases of NIV failure. Regarding nCPAP, Dargaville et al. ${ }^{8}$ reported that failed nCPAP is not superior to primary intubation. Their previous study also demonstrated that RDS is the single most important antecedent to nCPAP failure in preterm infants. ${ }^{9)}$ Likewise, early prediction 
Table 1. Perinatal characteristics, maternal medical history, outcomes, and causes of respiratory distress of 122 infants by study group

\begin{tabular}{|c|c|c|c|}
\hline Variable & $\begin{array}{l}\text { Success } \\
(n=109)\end{array}$ & $\begin{array}{l}\text { Failure } \\
(n=13)\end{array}$ & $P$ value \\
\hline \multicolumn{4}{|l|}{ Perinatal characteristic } \\
\hline Birth weight (g) & $2,130 \pm 461$ & $1,926 \pm 356$ & 0.126 \\
\hline Gestational age (wk) & $33.7 \pm 1.6$ & $32.9 \pm 1.4$ & 0.074 \\
\hline Cesarean section & $81(74.3)$ & $9(69.2)$ & 0.952 \\
\hline Male sex & $58(53.2)$ & $6(46.2)$ & 0.851 \\
\hline Small for gestational age & $19(17.4)$ & $3(23.1)$ & 0.905 \\
\hline Multiple birth & $25(22.9)$ & $6(46.2)$ & 0.139 \\
\hline Apgar score, $1 \mathrm{~min}$ & $7(5-8)$ & $6(5-7)$ & 0.085 \\
\hline Apgar score, 5 min & $8(8-9)$ & $8(7-9)$ & 0.292 \\
\hline Respiratory rate (min) & $55 \pm 22$ & $49 \pm 26$ & 0.365 \\
\hline CRP (above normal range) & $2(1.8)$ & $0(0)$ & - \\
\hline \multicolumn{4}{|l|}{ Maternal medical history } \\
\hline Antenatal steroid administration & $48(47.1)$ & $8(61.5)$ & 0.367 \\
\hline Chorioamnionitis & $8(7.3)$ & $0(0)$ & - \\
\hline Diabetes mellitus & $15(13.8)$ & $2(15.4)$ & 1.000 \\
\hline Hypertension & $27(24.8)$ & $5(38.5)$ & 0.467 \\
\hline Premature rupture of membranes & $34(31.2)$ & $4(30.8)$ & 1.000 \\
\hline Placental abruption & $8(7.3)$ & $0(0)$ & 0.676 \\
\hline \multicolumn{4}{|l|}{ Outcomes } \\
\hline Length of hospital stay (day) & $21.3 \pm 12.4$ & $38.2 \pm 46.3$ & 0.003 \\
\hline Duration of respiratory support (hr) & $54.3 \pm 35.0$ & $292.6 \pm 311.3$ & $<0.001$ \\
\hline Pneumothorax & $2(2)$ & $0(0)$ & - \\
\hline Surfactant usage & $0(0)$ & $9(69.2)$ & - \\
\hline BPD & $4(4)$ & $2(15)$ & 0.066 \\
\hline NEC & $1(1)$ & $0(0)$ & - \\
\hline Bacteremia & $0(0)$ & $0(0)$ & - \\
\hline PDA & $2(2)$ & $3(23)$ & $<0.001$ \\
\hline PVL & $0(0)$ & $0(0)$ & - \\
\hline IVH & $0(0)$ & $0(0)$ & - \\
\hline \multicolumn{4}{|l|}{ Causes of respiratory distress } \\
\hline $\mathrm{RDS}^{\mathrm{a})}$ & $27(24.8)$ & $10(76.9)$ & $<0.001$ \\
\hline $\mathrm{TTN}^{\mathrm{b})}$ & $76(69.7)$ & $1(7.7)$ & $<0.001$ \\
\hline Air leak & $0(0)$ & $0(0)$ & - \\
\hline Apnea & $1(1.0)$ & $0(0)$ & - \\
\hline
\end{tabular}

Values are expressed as mean \pm standard deviation, number of infants (\%), or median (interquartile range).

CRP, C-reactive protein; BPD, bronchopulmonary dysplasia; NEC, necrotizing enterocolitis; PDA, patent ductus arteriosus; PVL, periventricular leukomalacia; IVH, intraventricular hemorrhage; RDS, respiratory distress syndrome; TTN, transient tachypnea of the newborn.

${ }^{a)}$ RDS: diagnosed based on the clinical course, chest X-ray findings, and

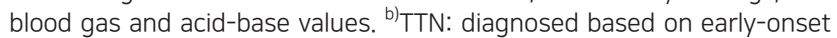
tachypnea and occasionally relieved by minimal 02 supply $(<40 \%)$.

Boldface indicates a statistically significant difference with $P<0.05$.

of BiPAP failure by checking the risk factors might enhance the efficacy of BiPAP, enabling prevention of additional morbidities in preterm infants.

Prenatal risk factors are important in the early prediction of NIV. In a study by Dargaville et al., ${ }^{8)}$ lower GA and BW, incomplete exposure to antenatal glucocorticoids, and cesarean section $(\mathrm{C} / \mathrm{sec})$ were prenatal risk factors for nCPAP failure in very and extremely preterm infants. We found no significant association between most prenatal characteristics and BiPAP failure.

In our study, RDS in moderate to late preterm infants was the single most important cause of respiratory distress in cases of BiPAP failure (Table 2). Most clinicians choose to administer surfactant in deteriorating courses of RDS. However, an evident pattern of RDS on a chest X-ray may be one of the fastest tools to predict BiPAP failure, as preterm infants in whom nCPAP fails were more likely to have chest X-ray findings consistent with severe RDS.9)

There was a data limitation regarding GA and BW due to unconditional and prophylactic surfactant administration via endotracheal tube in the delivery room. Rates of BiPAP failure in some studies differed widely (12.9\%-26.6\%). ${ }^{3-6)}$ Differences in inclusion criteria among studies might have caused differences in the BiPAP failure rates among studies.

To date, BiPAP support strategies are based on clinicians' decisions without a universal consensus. Our data showed that perinatal characteristics such as a lower GA and BW were not risk factors for BiPAP failure in infants born at a GA $\geq 30^{+0}$ weeks and $\mathrm{BW}>1,250 \mathrm{~g}$. Since RDS was significantly correlated with BiPAP failure, early detection of RDS aggravation is important to predict BiPAP failure.

Therefore, we concluded that for moderate to late preterm infants showing RDS aggravation on BiPAP regardless of GA or $\mathrm{BW}$, early changes made to invasive ventilator care or additional surfactant administration should be considered. In addition, increased oxygen and frequency requirements during BiPAP support may help identify preterm infants at high risk of BiPAP failure. Strategies to avoid NIV including BiPAP failure should be established; further multicentered well-designed randomized studies are needed to ensure the safety of BiPAP as the initial respiratory management approach for moderate to late preterm infants.

Heekwon Son, MD, Eui Kyung Choi, MD, Kyu Hee Park, MD, Jeong Hee Shin, MD, Byung Min Choi, MD, PhD

Department of Pediatrics, Korea University College of Medicine, Seoul, Korea

Corresponding author: Byung Min Choi, MD, PhD. Department of Pediatrics, Korea University Ansan Hospital, Korea University College of Medicine, 123 Jeokgeum-ro, Danwon-gu, Ansan 15355, Korea

凶 E-mail: cbmin@korea.ac.kr, https://orcid.org/0000-00030931-2353

\section{Conflicts of interest}

No potential conflict of interest relevant to this article was reported. 
Table 2. Characteristics of 122 infants receiving BiPAP

\begin{tabular}{|c|c|c|c|c|c|c|}
\hline \multirow{2}{*}{ Variable } & \multicolumn{2}{|c|}{ Univariate logistic regression } & \multirow{2}{*}{$P$ value } & \multicolumn{2}{|c|}{ Multivariable logistic regression (GA-adjusted) } & \multirow{2}{*}{$P$ value } \\
\hline & $\mathrm{OR}$ & $95 \% \mathrm{Cl}$ & & $\mathrm{OR}$ & $95 \% \mathrm{Cl}$ & \\
\hline GA & 0.955 & $0.908-1.005$ & 0.079 & & & \\
\hline Birth weight & 0.999 & 0.998-1.000 & 0.128 & & & \\
\hline Maximum PIP $\left(\mathrm{cmH}_{2} \mathrm{O}\right)$ & 19.633 & $1.789-215.411$ & 0.015 & 7.466 & $0.012-4695.296$ & 0.541 \\
\hline Maximum RR (min) & 1.411 & $1.130-1.763$ & 0.002 & 1.473 & $1.155-1.878$ & 0.002 \\
\hline Maximum $\mathrm{FiO}_{2}(\%)$ & 1.162 & $1.053-1.283$ & 0.003 & 1.129 & $1.038-1.433$ & 0.016 \\
\hline Post-BiPAP acidosis & 4.629 & $1.398-15.323$ & 0.012 & & & \\
\hline Post-BiPAP hypercardia & 6.929 & $1.996-24.050$ & 0.002 & & & \\
\hline Post-BiPAP pH $(\times 10)$ & 0.26 & $0.095-0.713$ & 0.009 & 0.265 & $0.013-5.576$ & 0.393 \\
\hline Post-BiPAP pCO2 (mmHg) & 1.09 & $1.028-1.156$ & 0.004 & 0.988 & $0.834-1.170$ & 0.887 \\
\hline $\mathrm{RDS}^{\mathrm{a})}$ & 10.123 & $2.594-39.503$ & 0.001 & 15.719 & $1.844-133.979$ & 0.012 \\
\hline
\end{tabular}

Post-BiPAP variables referred to blood gas analysis results within 2 hours after starting BiPAP.

BiPAP, bilevel positive airway pressure; GA, gestational age; OR, odds ratio; $\mathrm{Cl}$, confidence interval; PIP, peak inspiratory pressure; RR, respiratory rate; FiO2, fraction of inspired oxygen; $\mathrm{pCO}_{2}$, partial pressure of carbon dioxide; RDS, respiratory distress syndrome.

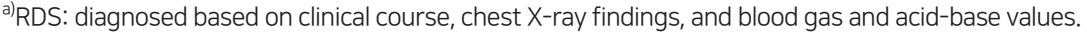

Boldface indicates a statistically significant difference with $P<0.05$.

\section{References}

1. Owen LS, Manley BJ. Nasal intermittent positive pressure ventilation in preterm infants: Equipment, evidence, and synchronization. Semin Fetal Neonatal Med 2016;21:146-53.

2. Committee on Fetus and Newborn; American Academy of Pediatrics. Respiratory support in preterm infants at birth. Pediatrics 2014;133:1714.

3. Solevåg AL, Kann IC. N-BiPAP treatment in infants with respiratory distress syndrome: a population study. Early Hum Dev 2015;91:577-81.

4. Salvo V, Lista G, Lupo E, Ricotti A, Zimmermann LJI, Gavilanes AWD, et al. Comparison of three non-invasive ventilation strategies (NSIPPV/ BiPAP/NCPAP) for RDS in VLBW infants. J Matern Fetal Neonatal Med 2018;31:2832-8.

5. Rong ZH, Li WB, Liu W, Cai BH, Wang J, Yang M, et al. Nasal bi-level positive airway pressure (BiPAP) versus nasal continuous positive airway pressure (CPAP) in preterm infants $\leq 32$ weeks: a retrospective cohort study. J Paediatr Child Health 2016;52:493-8.

6. Zhou B, Zhai JF, Jiang HX, Liu Y, Jin B, Zhang YY, et al. Usefulness of DuoPAP in the treatment of very low birth weight preterm infants with neonatal respiratory distress syndrome. Eur Rev Med Pharmacol Sci 2015;19:573-7.

7. Lista G, Castoldi F, Fontana P, Daniele I, Cavigioli F, Rossi S, et al. Nasal continuous positive airway pressure (CPAP) versus bi-level nasal CPAP in preterm babies with respiratory distress syndrome: a randomised control trial. Arch Dis Child Fetal Neonatal Ed 2010;95:F85-F89.

8. Dargaville PA, Gerber A, Johansson S, De Paoli AG, Kamlin CO, Orsini F, et al. Incidence and outcome of CPAP failure in preterm infants. Pediatrics 2016;138.

9. Dargaville PA, Aiyappan A, De Paoli AG, Dalton RG, Kuschel CA, Kamlin $\mathrm{CO}$, et al. Continuous positive airway pressure failure in preterm infants: incidence, predictors and consequences. Neonatology 2013;104:8-14. 